\title{
The extent of engagement, the means of invention: measuring debate about mirror neurons in the humanities and social sciences
}

\section{David R. Gruber}

Abstract

Keywords
Mirror neurons (MN) - or neurons said to be able to "mirror" the sensed environment - have been widely popularized and referenced across many academic fields. Yet, MNs have also been the subject of considerable debate in the neurosciences. Using a criterion based sampling method and a citation analysis, this paper examines the extent of engagement with the neuroscience literature about MNs, looking specifically at the frequency of "MN debate sources" within articles published in the JSTOR and Communication and Mass Media (CMMC) databases. After reporting the results, the paper reviews characteristic examples in context and, ultimately, shows that MN debates remain largely absent from peer-reviewed articles published in JSTOR and CMMC. However, the paper suggests that this happens for good reason and that MNs retain the potential for inventive animations even though debates have gone largely unrecognized.

Popularization of science and technology; Representations of science and technology; Scholarly communication

In a now famous accidental finding from 1992, cognitive neuroscientists from Italy observed neurons firing in the F5 motor area of a macaque monkey's brain both when the monkey saw an action as well as when the monkey performed that same action [di Pellegrino et al., 1992]. These special neurons were named "mirror neurons," suggesting the idea that the monkey might be internally "mirroring" its visual environment. Ever since, mirror neurons (MNs) have been touted as central to imitation [Caggiano et al., 2009; Rizzolatti et al., 1999], to predicting other people's actions [Gallese and Goldman, 1998; Gallese and Keysers, 2001; Goldman, 2006], and to expressing complex emotions [Damasio, 2003; Gallese, Keysers and Rizzolatti, 2004; Wicker et al., 2003]. Many popular news sources have applauded the discovery [Blakeslee, 2006; Brizendine, 2010; US News Staff, 2011; Science Daily Staff, 2007]. Accordingly, MNs proved exciting to scholars in the humanities and social sciences, especially in lieu of associations with imitation, empathy, affect, and embodied cognition.

This article examines levels of engagement with $\mathrm{MN}$ research across the humanities and social sciences. However, because MNs have been subject to a number of contentious scientific debates about their existence [Lingnau, Gesierich and 
Caramazza, 2009; Turella et al., 2009], their exact "mirroring" function [Csibra, 2005; Jacob, 2008; Hickok, 2009; Hickok, 2014; Michael, 2012], and their centrality to emotional processing [Murphy, Nimmo-Smith and Lawrence, 2003; Decety, 2010], the primary aim of this paper is to understand whether those controversies have found their way into the disciplinary uptake of $\mathrm{MN}$ research and affected that uptake, and if so, how.

Work on the knowledge-building processes of the burgeoning neuro-disciplines outside fields using neuroscience - has recently received some attention. Johnson and Littlefield [2011], for example, show how neuro-disciplines tend to give epistemological priority to neuroscience findings, situating neuro-disciplinary work as "fact-finding" and "theory-building" from the discoveries of neuroscience. Papoulias and Callard [2010] investigate the way that neuroscience research on affect is deployed in critical-cultural theory, arguing that brain research strengthens new ideas about affect but does not always align with the neuroscience texts cited. Gruber [2014] contends that Group Psychotherapy incorporates brain research by locating parallels in the descriptions used by neuroscientists - such as when "mirroring" neurons appear to support "mirroring therapy." However, no one has yet explored the relationship between scientific controversy and disciplinary uptake, nor has anyone explored how "outside" disciplines negotiate debate about neuroscience findings.

Research in Science Studies, Sociology, and Rhetoric has explored how scientific controversy shapes public discourse [Brewer and Ley, 2011; Friedman, Dunwoody and Rogers, 1999; Gregory and Miller, 1998; Priest, 2006]; yet, little research has explored how scientific controversy affects the way that science deployed in academic or professional settings. One exception might be Robert Proctor's [2008] study of "agnotology." He argues that scientific controversy filtered through effective marketing does impact public health perceptions and recommendations and, thus, provides an indication that a manufactured controversy may influence how and whether science is used outside of scientific domains [p. 96]. But by and large, the relationship between controversy and subsequent disciplinary or technical development is uncharted.

By sampling articles engaging MNs across humanities and social sciences fields from two time periods that correspond with the rise of MNs and the presence of MN debates in the neurosciences (1992-2007 / 2008-2013), I show that debates about MNs are just now emerging (in humanities and social science contexts) but still remain poorly represented. I ultimately argue that sources highlighting MN debates are largely absent from articles in the humanities and social sciences for three reasons.

- First, the sampled humanities and social sciences articles emphasize founding research alongside of popular texts about MNs. I suggest that these choices are fitting for disciplinary and rhetorical development and may be the most visible and accessible for uninitiated researchers.

- Second, the sampled humanities and social sciences articles appeal repeatedly to the same three neuroscience researchers - Vittorio Gallese, Giacomo Rizzolatti, and Marco Iacoboni. Thus, I argue that these important, founding MN researchers have formed what Bruno Latour [1987; 1997; 2005] calls a 
"network" of rhetorical "alliances," sufficiently publicizing and protecting early simulation theory claims about MNs, at least until quite recently.

- Third, many articles seek new ecological conceptions. MNs are made compatible with the current drive to re-conceptualize the human as a network of entwined co-being amid the disciplinary desire to move beyond post-structuralism and locate a basic identification with "the Other" through non-semiotic and non-linguistic processes. Adoption of the "Action Understanding Theory" of MNs - which situates MNs as a simulation "mirroring" mechanism in the brain that intimately unites people and helps them understand each other through embodied simulation - proves useful to overcoming post-structuralist limitations. Engaging debate against mirroring would complicate the reason for turning to MNs in the first place.

Ultimately, I aim to make a positive statement: MNs retain the potential for inventive animations across the humanities and social sciences even though debates have gone largely unrecognized. Through alignments with embodied cognition and generalizable connections to entwined relations, MNs have allowed interested scholars to compose a myriad of field-specific extensions in theoretical and applied work. This is demonstrated in a brief review of how the sampled articles from Linguistics, Visual Communication, and Literary Studies have used MNs in compelling ways despite deploying essentially the same citations supporting a direct simulation framework. Interestingly, then, the popularity of the mirroring effect and the limited way that mirror neurons are introduced does not necessarily prevent theoretical invention in the humanities and social sciences, despite the loss of other possibilities when MNs are so circumscribed. What a combination of field-specific invention plus lack of debate means for future engagement with MNs in the humanities and social sciences will be explored in the conclusion.

Using a criterion-based sampling method [Merriam, 1998], a set of peer-reviewed journal articles were sampled from the JSTOR and Communication and Mass Media Complete (CMMC) databases ${ }^{1}$ using the search term "mirror neurons" and searching only humanities and social sciences articles. The criteria took into account article content, date of publication, and journal of publication.

Consequently, the articles needed to contain discussion of MNs from neuroscience sources. For this criterion, when searching the CMMC database, MNs had to appear as a subject term describing the article; given JSTOR's differing search capabilities, articles had to mention MNs in the titles and abstracts in order to be included in the sample. In both cases, articles needed to contain citations from neuroscience journals addressing MNs. All sampled articles also needed to be published after the first MN discovery and needed to appear in a peer-reviewed journal associating with the humanities or social sciences. ${ }^{2}$ The search was, thus, divided into two steps.

\footnotetext{
${ }^{1}$ Both databases were chosen because they act as the primary 'go-to' database for the author's home field of study, i.e. Rhetoric and Communication Studies. In this way, the author prioritized the database s/he was most likely to use and, thus, located the articles s/he was most likely to find if researching MNs.

${ }^{2}$ If journals did not clearly associate with the humanities or social science or if articles were published by neuroscientists as the lead author, then those articles were eliminated from the sample. If questions about a journal's affiliation arose, then the researcher reviewed the journal's homepage and self-description.
} 
The first step entailed searching for articles published between 1992 and 2007 while the Action Understanding Theory of MNs was dominant despite, perhaps, some lingering questions about its efficacy. The second step entailed locating articles published between 2008 and 2013, after debates had solidified. In total, eight articles from the first period matched the criteria, all of which appeared in the CMMC database. Fifteen articles appeared from the second time period, eleven from the CMMC database and four from JSTOR.

From the second time period (2008-2013), only the first eight that matched the criteria from the CMMC database, taken in order of relevance, were selected in order to facilitate a direct numerical comparison regarding the overall number of sources and the types of sources. ${ }^{3}$ The four JSTOR sources published in the 2008-2013 time period were also considered in subsequent results, primarily as a point of interest when compared to the CMMC database.

I then counted the total number of MN citations in each article by searching for the term "mirror neurons" in the body of the text and counting the citations individually. This method allowed me to gain a sense of what was being cited (and who) when mirror neurons were mentioned. However, to ensure all neuroscience citations exploring MNs were counted, I ultimately visited the bibliography pages of each article and counted MN articles published from neuroscience journals and/or books. ${ }^{4}$ The goal here was to develop a thorough understanding of total $\mathrm{MN}$ sources and to compare total sources detailing MNs to sources raising concerns about MNs.

To facilitate a comparison, I isolated 12 neuroscience articles highlighting problems with MNs. As a scholar familiar with $\mathrm{MN}$ research, I used my own knowledge as well as conducted new searches for MN controversies to locate relevant, high-profile neuroscience articles, termed "debate sources." I then attempted to see if such sources appeared in the sampled texts. The so-called "debate sources" are as follows: Tai et al. [2004], Csibra [2005], Mahon and Caramazza [2005], Negri et al. [2007], Jacob [2008], Lingnau, Gesierich and Caramazza [2009], Turella et al. [2009], Hickok [2009], Hickok and Hauser [2010], Decety [2010], Kosonogov [2012] and Michael [2012].

Important to note is the fact that debates about the Action Understanding Theory of MNs did not receive much attention until 2005 with Gergely Csibra's article, asking, "Is simulation involved?" Likewise, the 2005 Negri et al. article posed a similar question. The Tai et al. article [2004] showed that MNs did not fire in response to robotic arms, and thus, the article raised questions about the extent of MN functioning and the role of MNs in understanding actions; this is the earliest article that one might expect to find in the sample from the first time period. ${ }^{5}$ In

\footnotetext{
${ }^{3}$ The number of total articles published was not as pertinent to the study as the number of sources used in sampled articles as well as which MN sources were being cited in the sampled articles taken in order or most relevant results.

${ }^{4}$ Neuroscience books needed to have a neuroscientist as the lead author to be deemed a neuroscience book. Also, MN sources were counted if they were written by a neuroscientist, published in a neuroscience journal, and discussed MNs. In most cases, this could be done by reviewing titles and abstracts. If a question arose, visiting the article facilitated a qualitative decision by the researcher.

${ }^{5}$ Umiltà et al., published a famous article in 2001 that showed some limitations to MNs, but that article largely supported the Action-Understanding Theory and has been used by Vittorio Gallese and others to promote the theory; consequently, I did not list that article as a debate source.
} 
short, if taking these articles as a turning point in $\mathrm{MN}$ discussions, then one might expect not to see debates - or ones specifically questioning simulation/mirroring theories - until the end of the first time period (1992-2007) or the start of the second time period (2008-2013). These articles provided the guideline for grouping these sources, allowing comparisons of the number and type of sources across the appearance of $\mathrm{MN}$ debates.

The starting hypothesis was that scholars working in the humanities and social sciences would use mostly older MN sources to establish the phenomenon but would be strategically avoiding or be unaware of problematic or alternative interpretations of MNs in the neurosciences, displaying no citations for debate sources across either time period.

The results, firstly, indicate growth over time in the total number of $\mathrm{MN}$ sources used in the articles sampled. In the CMMC database, $46 \mathrm{MN}$ sources were cited across 8 articles published between 1992-2007, and 72 total MN sources were cited from the 8 articles published between 2008-2013. In the JSTOR database, no articles that fit the criteria appeared before 2010. In total, $26 \mathrm{MN}$ sources appeared across the four JSTOR articles, which were all published in 2010 or 2011.

Secondly, the results in the chart show that over half of all MN sources from all sampled articles were written by one of three founding MN neuroscientists advancing the Action-Understanding Theory of MNs (59\%, N=86); those three authors include: Vittorio Gallese, Giacomo Rizzolatti, and Marco Iacoboni. Articles from these authors account for 20 of 26 total MN sources sampled from JSTOR.

With respect to the hypothesis, the results indicate extremely limited engagement with MN debates in the sampled articles prior to 2008. One source from 2006 includes one citation from Tai et al. [2004]. A slight increase in the number of

Comparing Total MN Sources in Humanities and Social Science Articles to Sources Authored by Three Core Action-Understanding Theorists

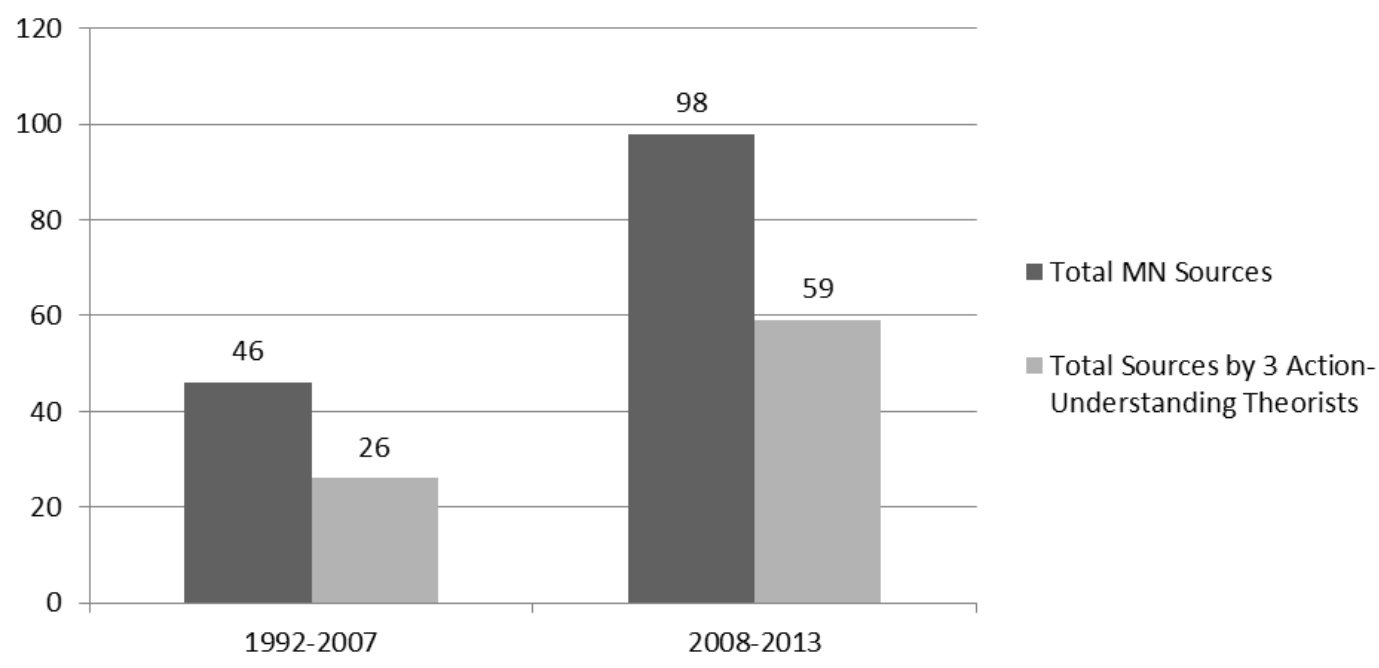

Chart 1. Types of MN Sources Over Time. 
debate sources occurred after 2008. However, in total, only three different "debate sources" were referenced in six total citations between 2008-2013 across four articles. Those articles were published in 2010, 2011, or 2013 respectively. One article cited three of the debate sources, and the remaining three articles each cited one - all of those citing Hickok, 2009. The debate sources referenced from this time period included: Hickok [2009], Hickok and Hauser [2010] and Lingnau, Gesierich and Caramazza [2009]. ${ }^{6}$

Finally, while reading the articles, the researcher qualitatively observed the occurrence of popular books and news articles about neuroscience written by figures such as Michael Corballis, Antonio Damasio, Terrence Deacon, Merlin Donald, Marco Iacoboni, and V.S. Ramachandran. Thus, in the sampled articles, all popular sources written by these authors were also counted. A total of 11 popular source citations from seven different popular sources appeared across 8 of the 16 sampled articles with one article citing both popular sources and debate sources. ${ }^{7}$

Although the sample size is small, the data comes from two library databases with wide readership and holdings from the humanities and social sciences; scholars from media studies, rhetoric, cultural studies, communication and such fields are likely to encounter these sources when searching for MNs. The sample is, in that respect, reasonably representative of the disciplinary engagement with MNs given the likelihood that researchers access these databases. Even so, the claims that this essay can make cannot be widely extended and can only be directed to the uptake of MN research in the texts represented in the JSTOR and CMMC database specifically.

Nevertheless, the study offers the intriguing possibility that scholars from the humanities and social sciences seeking to engage MNs may increase their exposure to neuroscience texts with time as debates become publicized and circulated. The increase in sources used over time, indicates, perhaps, that quick references to founding sources alone prove no longer sufficient. In fact, looking only at the CMMC database (since JSTOR provides no sampled texts from before 2010), the average number of MN sources from the first time period (1992-2007) was 6 while the average from the second time period (2008-2013) was 9. The increase over such a short period of time is correlated with a rise in the availability of debate sources. The increase is also correlated, of course, with a general surge in all sources about MNs as time passes. Regardless, the number of sources employed with respect to MNs rises with time.

The alternative perspective on this increase is that scholars from the humanities and social sciences have ignored $\mathrm{MN}$ debates, and any increase in the number of overall sources indicates little in terms of improvement or wide and deep investigation of the neuroscience literature. A closer look at the sampled texts is needed to comprehend the extent of engagement and to understand how the debate sources function in the texts themselves.

\footnotetext{
${ }^{6}$ Only one debate source was located in the JSTOR database. All others come from CMMC.

${ }^{7}$ These popular books were counted as 'MN sources' and included in earlier figures. Also note: to determine "popular" books, I looked at the titles, which seemed to speak for themselves. Examples include: "The lopsided ape" by Michael Corballis, "Descartes' error: Emotion, reason, and the human brain" by Antonio Damasio, "Mirroring people" by Marco Iacoboni, etc.
} 
Ultimately, looking across all of the MN sources referenced, the early sources supporting the Action-Understanding view of MNs tend to prop up discussion alongside of popular neuroscience texts. This leads to the suggestion that three researchers, in particular, guide significant discussion about MNs, illuminating the relevance of MNs for many of the articles. Looking at all cases where debate sources were referenced, debate remains widely absent. Only one article in the entire sample gives sustained voice to the debate in the text itself and/or recognizes its impact on the meanings that can be ascribed to MNs. In short, the sampled articles overlook important MN debates published in top neuroscience journals. However, as will be discussed, the authors have reason for doing so and, ultimately, invent theories for their respective fields from within the validity and excitement of the early Action Understanding Theory of MNs. Whether that remains good enough for future interactions with the neurosciences is another question.

\section{Citing MN Sources and Eliding Debate}

A majority (59\%) of all MN sources cited across all texts sampled were written by one of three researchers - Vittorio Gallese, Giacomo Rizzolatti, and Marco Iacoboni. If one were to also include other neuroscience researchers supporting the Action Understanding Theory of MNs, the number would be significantly higher. There are several explanations for this observation.

Most notably, the original, founding researchers must be cited in a discussion of MNs. This is an issue of establishing the meaning and legitimacy of the original MN finding. As Jenny-Anne Brodin Danell notes, citations are used "to position the research (e.g., in relation to traditions and research groups), pay respect, and show communality or distance" [Danell, 2012, p. 302]. The interesting point is that these humanities and social sciences articles tend to show communality and not distance. All but one article in the sample either cite founding MN texts exclusively or pair them with reifications of the Action Understanding Theory without recognition of serious criticisms.

For example, looking across the texts starting from 2007, six of the thirteen articles in that time period cite a handful of early MN sources exclusively, effectively establishing the MN finding and then working from their own field-specific sources [See: Aboitiz, Aboitiz and García, 2010; Connolly, 2011; Griggers, 2009; Jajdelska et al., 2010; Pardo, 2012; Powell, 2007]. ${ }^{8}$ The remaining articles cite sources up through 2011 that continue to support the Action Understanding Theory [including MN sources such as: Arbib, 2005; Dapretto et al., 2006; Corballis, 2005; Fogassi, 2011]. The articles also turn to sources informed (i.e., authored or co-authored) directly by Gallese or Iacoboni written well after the MN debates had arisen, post 2004. This includes sources such as: Iacoboni [2008], Mukamel et al. [2010] and Rizzolatti and Craighero [2006]. As noted, four of the articles published between 2008-2013 do cite "debate sources," but in only one case is a debate source recognized as such.

\footnotetext{
${ }^{8}$ The Pardo 2012 article does not recognize debates as such and cites none of the debate sources, but Pardo does mention Hickok's view of brain processing from a 2010 article that Hickok published; however, Hickok's article is detailed as another account of how speech perception can be different than speech production. In other words, the direct connection to MNs is difficult to pin down here. Even so, in my view, Pardo's article is a good example of strong engagement with neuroscience literature writ large even though the extent of MN discussion may be sparse.
} 
Several articles do not discuss MN debates despite citing a debate source. A 2013 article by Christy Craig entitled, "Vygotsky, Cognitive Development and Language" cites Gregory Hickok's 2009 article reviewing ten problems with MNs. The article, however, employs Hickok's scathing review of the Action Understanding Theory of MNs to uphold the idea of a body-world coupling which can support Vygotsky's views. In other words, Hickok's critique is positioned merely to argue that MNs alone cannot account for Vygotsky's discussion of human cognitive development. Hickok's ten different critiques are thusly condensed to show that the external environment is also needed for body-world couplings or for MNs to function properly [see Christy, 2013, pp. 207-208].

Similarly, in a 2011 article by Charles Berger entitled "Listening is for Acting," Hickok is cited again in the final sentence in a large paragraph about MNs, but the critique is ultimately disregarded. Berger frames Hickok's contribution less as a condemnation of the Action Understanding Theory and more as a way to move past any debilitating debate, which threatens to close down the purpose for turning to MNs. Berger states, "some critics have argued that action understanding can be achieved through brain circuits that apparently do not contain mirror neurons [Hickok, 2009]. " The next sentence, which appears in the following paragraph, then returns back to Vittorio Gallese. Berger states, "Nonetheless, automatic mimicry and anticipatory neural activity in mirror neurons may partially explain why social interaction can be carried out relatively smoothly, even though social actors may speak rapidly and quickly switch conversational roles from speaker to listener [Gallese, 2009; Pezzulo and Castelfranchi, 2009, p. 106]." The Berger article, thus, reigns in the power of MNs to some extent but still upholds the Action-Understanding Theory without engaging Hickok's critiques.

Among all of the articles in the sample, only Matthew Traxler's 2013 article about language comprehension deals substantively with MN debates [Traxler, 2013]. The article provides a strong review of $\mathrm{MN}$ literature followed by a discussion of philosophical issues about language, suggesting several possible roles of MNs given the various, sometimes conflicting, neuroscience studies.

\section{Strengthening Actor-Networks of MN Researchers}

Embracing the Action Understanding Theory may reflect a perception of a scientific consensus around that particular interpretation of MNs. This is understandable given the long time frame in which Gallese, Rizzolatti, and Iacoboni, among others, explored and publicized the finding in that respect (since the mid-1990s). Indeed, if viewed from the perspective of Science and Technology Studies, a set of related, intertwined researchers and citations can, following Bruno Latour's Actor-Network Theory [1987; 1997], be understood as an "actor-network" that achieves the work of consensus. For other disciplines interested in neuroscience, appealing to that actor-network becomes, for their field-specific audiences, a process of persuasive recruitment where citations stand-in for entire "networks" of related researchers, disciplines, technologies, and institutions, becoming what Actor-Network Theorist Michael Callon [1991] calls "punctualized actors" that strengthen the text's argument.

Thinking this way about citations means that texts are made, in part, by recruiting "allies" through citations, strengthening the text's acceptability to an audience, and 
forging permeability [Latour, 1997, p. 180]. The fact that more than half of all citations come from only three researchers who have, broadly and essentially, agreed on $\mathrm{MN}$ interpretations exposes a functioning actor-network and one visible to other disciplines. The further fact that those researchers figure prominently in the discovery and development of Action Understanding, along with the theory's prominence in the neurosciences between the mid-1990s and late-2000s, lends reason for scholars outside the neurosciences to adopt the related citations.

Additionally, since Gallese, Rizzolatti, and Iacoboni continue to produce high-profile publications, they may have inadvertently diminished the visibility of other sources lacking their own functioning actor-networks (collections of like-minded researchers pursuing the same goal and well-funded to do so). Whatever the case, the failure to meaningfully include alternative theories and debate sources being published in high-profile journals like Cognitive Neuropsychology [Negri et al., 2007], the Journal of Cognitive Neuroscience [Hickok, 2009], the Proceeding of the National Academy of Sciences [Lingnau, Gesierich and Caramazza, 2009], and Current Biology [Hickok and Hauser, 2010] raises concerns about the time and/or desire and/or capacity of scholars from the humanities and social sciences to deeply engage the literature of the neurosciences.

However, criticizing scholars for not citing or discussing debate sources needs to be a carefully measured affair. As gesture studies researcher Anna Kuhlen [2014] states in an interview about her own cross-disciplinary work: "it's just asking too much of people to be an expert in both fields. You can't be up to date on all the neuroscience literature and at the same time be up to date in the field that you come from, or vice versa. It's also partially just the way our career system works. We don't have the time to be reading all these articles and be truly an expert in both fields" [p. 1]. Moreover, critiquing scholars for not engaging debates may underestimate the sheer number of MN sources that advanced or applied or extended some version of the Action Understanding Theory of MNs. For instance, a recent search on the Scopus database for "Action Understanding Theory," limited to neuroscience and biochemistry journals only, revealed 412 results. The same search for "mirror neuron problems" yielded 50 results. Any potential condemnation of fields unproblematically adopting the Action Understanding thesis without also recognizing problems or debates must be measured against such observations.

\section{Making MNs Fit New Ecological Conceptions}

Outside of debate sources being potentially less visible, the majority of humanities and social sciences articles in this sample that explore MNs do so because the authors advance ecological conceptions and/or tie semiotic concerns to dynamic processes with feedback loops between Self, others, and the material world. As Rick Dolphijn and Iris van der Tuin [2012] note in explaining why cultural theorist Manuel DeLanda, among others, embraces new material entanglements: "postmodernism or linguisticist idealism has led us away from theorizing scholarly processes as material processes, and as having dynamic, morphogenetic capacities of their own" [p. 15]. The postmodern, deconstructionist days of promoting social and historical analysis of language and meaning-making processes has pushed scholars away from adequately engaging the persuasive and important contributory attributes of the material world. MNs aid the inevitable (reverse) shift. 
Sociologist Patricia Clough [2008] makes a similar observation, suggesting that an "affect turn" in the humanities "did propose a substantive shift in that it returned critical theory and cultural criticism to bodily matter which had been treated in terms of various constructionisms under the influence of post-structuralism and deconstruction. The turn to affect points instead to a dynamism immanent to bodily matter and matter generally" [p. 1]. Likewise, rhetorical scholar Thomas Rickert [2012] argues in his book Ambient Rhetoric for ecological thinking in light of new technological environments. In his words: "an ambient age calls us to rethink much of our rhetorical theory and practice, indeed, calls us to understand rhetoric as ambient," by which he means environmental, interactive, and living [p. 3]. A new move to re-engage the material world, to embrace the sciences amid a recognition of disciplinary limits and practices, now circulates throughout the humanities and social sciences. Similar feelings and notions motivate the sampled articles.

Three examples are worth detailing to make the point. In a 2006 article entitled, "Walking and talking: Traces of the body in the grammar and lexis of spontaneous spoken English," the authors argue that "hominid ancestors" may have shifted strategies for communication due to new diets and new environments and, consequently, the human brain developed language. The argument is made while drawing heavily from Michael Corballis, Terrence Deacon, and Vittorio Gallese, suggesting ultimately that "ritual," gesture, and "grounded concepts" led to language development [p. 343-344]. Here, embodied cognition invests in evolutionary processes, offering a theoretical role for MNs. Interestingly, Gregory Hickok, in his 2014 book, The Myth of Mirror Neurons, argues that this inherent or presupposed tie between a gesture-based model of speech and MNs wrongly provided a basis for the Action Understanding Theory of MNs from the very beginning; in Hickok's view, such a connection is untenable and unproven. Yet, the case remains: MNs are folded into embodied cognition to act as an explanatory mechanism for language and linguistics. MNs seem to help explain the emergence of language from an ecological, materialist perspective that positions the body, and rightly so, as entwined with the environment. MNs, in a sense, construct a bridge for ecological explanations.

In another article from the CMMC database sample, Mirror neurons: How we become what we see [2009], visual communication researchers state, "mirror neurons pave the way for understanding such diverse phenomena as the evolution of language, emotional empathy in interpersonal communication, and personal social identity and coherence" [p. 79]. They then proceed to state, "Mirror neuron research is clear. The likelihood of our imitating the violence we see may depend on the individual strength or weakness of the action-governing super mirrors which mediate cognitive resistance to imitation" [p. 86]. The article draws primarily from two of Damasio's popular books, a New York Times article about MNs, six different articles by Vittorio Gallese, and a list of other MN sources by Ramachandran and Iacoboni supporting the Action Understanding Theory. No citations raising concerns about MNs are included despite the date of publication, and human behavior is interpreted broadly through the simulation framework which positions MNs as driving reactive impulses - alongside of little discussion of the social semiotics that, in former days of postmodern post-structuralism, might have, rather, dominated the discussion in a journal like Visual Communication Quarterly. 
Finally, in an article from literary studies entitled, "Crying, Moving, and Keeping It Whole: What Makes Literary Description Vivid?," Elspeth Jajdelska and colleagues [2010] set out to chart the relationship between literary description and "real-life perception" [p. 435]. They want to show that "mental imagery and affect are inextricably linked" in order to develop a "theory of vividness in one kind of literary description - that of faces" [p. 435]. This is achieved, as they state, using scientific evidence and specifically, "new work on the relationship among interpretation, emotion, and mirror neurons" [p. 437]. The aim, in itself, exposes an underlying ecological disposition that turns to brain science to bolster traditional analysis of literature. Brain science here offers new evidence for literary claims working from audience responses. Appeals to Andy Clark [1995], Gallese [2003], and Rizzolatti and Craighero [2004] support the discussion. No "debate sources" appear in the article. Yet, the move to consider ties between mentalization and affect seems to add to the field of literature.

Conclusion: field-specific inventions and omissions
Despite the overall lack of engagement with MN debates, scholars working within the humanities and social sciences seemingly have good reason to support and/or explore the possibilities of the Action Understanding Theory. Not only was it the most popular, publicized, and dominant view for a long time, but it also enabled the broader effort to move beyond the limits of post-structuralism and to locate ecological approaches and explanations to human behavior, specifically with respect to language and persuasion. Given the flurry of recent materialist "turns" in the humanities and social sciences - a turn toward the body, affect, and the environment [See: Blackman, 2012] — discussing the Action Understanding Theory and citing researchers such as Gallese, Rizzolatti, and Iacoboni seems reasonable and productive. Indeed, it is important to remember, as Gilbert [1977] observes, authors in many disciplines "choose to cite articles they recognize to be authoritative in order to justify the validity, novelty, and significance of their own works" [p. iii]. The authors of the sampled articles do this quite well.

Additionally, the lack of MN debate and the general adoption of the Action Understanding Theory of MNs in the humanities and social sciences do not necessarily lead to a poverty of invention with respect to theory. Quite the contrary. MNs are employed creatively and in ways that allow for new questions to be asked within field-specific discourses. Although the articles discussed above cite many of the same sources and view MNs in essentially the same terms, they still, nevertheless, invent new ideas and chart new directions within their fields.

For example, Anne Marie Barry [2009] suggests that violence is learned through MNs, and in so doing, she argues for reconsidering the effect of images on varied types of audiences and speculates about the importance of understanding empathy in relation to images [p. 87]. Despite forwarding a highly inscribed view of MNs, the article provides something of a move forward, I would argue, because the intellectual position that Barry takes compels researchers in the humanities to examine the body and biological systems within accounts of persuasion. The same is true for Jajdelska and colleague's [2010] scientific literary analysis.

Likewise, making the suggestion that language is tied to gesture and that language only appears after a shift in hominid eating habits, just as Robin Melrose does in her 2006 article, seeks after new areas of inquiry even if it does not need to be 
related to a specific interpretation of MNs. Generally, the view encourages scholars interested in language to reconsider its strange ties to the body and to the world of animals and plants. Connecting the body in this way to language proves important now more than ever as fields from Psychotherapy to Game Studies explore gesture and mediated environments, intending to fold them into accounts of meaning-making such that language is no longer an isolated and exclusive variable in practice or analysis.

This overall impulse to generate new theoretical inventions within the burgeoning neuro-humanities and neuro-social sciences may lead to strategic decisions regarding neuroscience sources. As Stephen Ramsay [2011] points out amid a discussion about including computational processes from the sciences into the humanities, "science differs significantly from the humanities in that it seeks singular answers to problems under discussion... In the humanities the fecundity of any particular discussion is often judged precisely by the degree to which it offers ramified solutions to the problem at hand" [p. 15]. Ramsay's passage raises two considerations with respect to MN sources and a lack of MN debates across the texts sampled.

First, making choices about when to use MNs and how to situate them in relationship to on-going conversations within a field may be both practical and political. Neuroscience sources offer solutions insofar as they provide explanatory mechanisms and secure epistemological legitimacy for theoretical and social commentary. One discipline's concern with the "correctness" of scientific mechanisms, presumably, helps the other discipline's concern with expanding meanings, discovering new conversational avenues, and narrating the human experience. Put another way, neuro-disciplinary scholars likely seek not to promote a singular scientific reality as much as field-specific agendas through inter/cross-disciplinary inventions.

Second, Ramsay's passage exposes how scholars from non-science disciplines may not be prepared or willing to become enmeshed in debates about scientific issues. There is no evidence to suggest that any of the authors of the texts explored in this study did not know about the MN debates; they might have strategically avoided them. Since specialized lines of inquiry and judgments of value come from home departments and field-specific journals, the authors can hardly be blamed for tepid engagement with competing "realities" formed from different questions within what Karin Knorr Cetina [1999] deems other "knowledge societies" [p. 5]. The neuro-disciplines are not, after all, necessarily engaged in "transdisciplinary" projects wherein stakeholders solve problems together [Groß and Stauffacher, 2014, p. 299]. As Jenell Johnson and Melissa Littlefield [2011] indicate, many humanities scholars set out to find and use neuroscience as a means toward "providing answers to what are typically seen as open-ended questions" [p. 289]. In this respect, delving into debates is outside the range of intent and quite possibly familiarity.

With that said, a limited scope of research constructs its own heights and depths. If this initial study of sources and citations is any indicator, then there remains little doubt that the humanities and social sciences could still do better at engaging neuroscience literature. Of course, the only way to do that is to do that. A lot of time and, perhaps, close partnership with those working within the neurosciences 
is required. A directed search for problems and debates with article sections specifically dedicated to problems and debates would also likely benefit the neuro-disciplines / neuro-humanities-social sciences.

The good news, though, is that fields seem to benefit from engaging the brain and may still be capable of advancing their causes simply as a consequence of seeking cross-disciplinary expansions despite what is included and excluded. Even so, if a viable future for new theories or practices dependent upon neuroscience research is to be made, then an inclusive approach is likely the best approach - one that seeks out contentions within the relevant, respected communities and does not risk, as the old adage goes, building a house upon the sand.

\section{References}

Aboitiz, F., Aboitiz, S. and García, R. R. (2010). ‘The Phonological Loop: A Key Innovation in Human Evolution'. Current Anthropology 51 (S1), S55-S65. DOI: $10.1086 / 650525$.

Arbib, M. A. (2005). 'From monkey-like action recognition to human language: an evolutionary framework for neurolinguistics'. The Behavioral and Brain Sciences 28 (2), pp. 105-124.

Barry, A. M. (2009). 'Mirror neurons: how we become what we see'. Visual Communication Quarterly 16 (2), pp. 79-89. DOI: 10.1080/15551390902803820.

Blackman, L. (2012). Immaterial bodies: Affect, embodiment, meditation. London, U.K.: Sage.

Blakeslee, S. (10th January 2006). 'Cells That Read Minds'. The New York Times. URL: http://www .nytimes.com/2006/01/10/science/10mirr.html.

Brewer, P. R. and Ley, B. L. (2011). 'Multiple Exposures: Scientific Controversy, the Media, and Public Responses to Bisphenol A'. Science Communication 33 (1), pp. 76-97. DOI: 10.1177/1075547010377879.

Brizendine, L. (25th March 2010). Love, sex and the male brain - CNN.com. URL: http://edition.cnn.com/2010/OPINION/03/23/brizendine.male. brain/inde x.html?iref=allsearch (visited on 10th May 2012).

Caggiano, V., Fogassi, L., Rizzolatti, G., Thier, P. and Casile, A. (2009). 'Mirror neurons differentially encode the peripersonal and extrapersonal space of monkeys'. Science 324 (5925), pp. 403-406. DOI: 10.1126/science.1166818.

Callon, M. (1991). 'Techno-economic networks and irreversibility'. In: A sociology of monsters: essays on power, technology and domination. Ed. by J. Law. London, U.K.: Routledge.

Christy, T. C. (2013). ‘Vygotsky, Cognitive Development and Language: New perspectives on the nature of grammaticalization'. Historiographia Linguistica 40 (1), pp. 199-227. DOI: 10.1075/hl.40.1-2.07chr.

Clark, A. (1995). 'I Am John's Brain'. Journal of Consciousness Studies 2, pp. 144-148.

Clough, P. T. (2008). 'The Affective Turn: Political Economy, Biomedia and Bodies'. Theory, Culture \& Society 25 (1), pp. 1-22. DOI: 10.1177/0263276407085156.

Connolly, W. E. (2011). 'The Complexity of Intention'. Critical Inquiry 37 (4), pp. 791-798. DOI: $10.1086 / 660993$.

Corballis, M. C. 'Language as gesture'. Human Movement Science 28 (5), pp. 556-565. DOI: $10.1016 / j$.humov. 2009.07.003.

Csibra, G. (2005). 'Mirror Neurons and Action Observation. Is Simulation Involved?' Interdisciplines Jan, pp. 1-5.

Damasio, A. (2003). 'Feelings of emotion and the self'. Acad. Sci. 1001, pp. 253-261. 
Danell, J.-A. B. (2012). 'Representation and Negotiation of Complementary and Alternative Medicine A Citation Context Analysis'. Science Communication 34 (3), pp. 299-333. DOI: 10.1177/1075547011413140.

Dapretto, M., Davies, M. S., Pfeifer, J. H., Scott, A. A., Sigman, M., Bookheimer, S. Y. and Iacoboni, M. (2006). 'Understanding emotions in others: mirror neuron dysfunction in children with autism spectrum disorders'. Nature Neuroscience 9 (1), pp. 28-30. DOI: $10.1038 / \mathrm{nn} 1611$.

Decety, J. (2010). 'To What Extent is the Experience of Empathy Mediated by Shared Neural Circuits?' Emotion Review 2 (3), pp. 204-207. DOI: 10.1177/1754073910361981.

di Pellegrino, G., Fadiga, L., Fogassi, L., Gallese, V. and Rizzolatti, G. (1992). 'Understanding motor events: a neurophysiological study'. Experimental Brain Research 91 (1), pp. 176-180. DOI: 10.1007/BF00230027.

Dolphijn, R. and van der Tuin, I. (2012). New Materialism: Interviews and Cartographies. London, U.K.: Open Humanities Press.

Fogassi, L. (2011). 'The mirror neuron system: how cognitive functions emerge from motor organization'. Journal of Economic Behavior \& Organization 77 (1), pp. 66-75. DOI: 10.1016/j. jebo.2010.04.009.

Friedman, S. M., Dunwoody, S. and Rogers, C. L. (1999). Communicating Uncertainty: Media Coverage of New and Controversial Science. Mahwah, U.S.A.: Lawrence Erlbaum Associates.

Gallese, V. and Goldman, A. (1998). 'Mirror neurons and the simulation theory of mind-reading'. Trends in Cognitive Sciences 2 (12), pp. 493-501.

Gallese, V. (2003). 'The manifold nature of interpersonal relations: the quest for a common mechanism'. Philosophical Transactions of the Royal Society of London B: Biological Sciences 358 (1431), pp. 517-528. DOI: 10.1098/rstb. 2002.1234.

- (2009). 'Mirror Neurons, Embodied Simulation, and the Neural Basis of Social Identification'. Psychoanalytic Dialogues 19 (5), pp. 519-536. DOI: 10.1080/10481880903231910.

Gallese, V. and Keysers, C. (2001). 'Mirror neurons: A sensorimotor representation system'. Behavioral and Brain Sciences 24 (5), pp. 983-984. URL:

http://journals . cambridge. org/action/displayAbstract? fromPage=online \&aid=125170\&fulltextType=SC\&fileId=S0140525X01350112.

Gallese, V., Keysers, C. and Rizzolatti, G. (2004). 'A unifying view of the basis of social cognition'. Trends in Cognitive Sciences 8 (9), pp. 396-403. DOI: 10.1016/j.tics.2004.07.002.

Gilbert, G. N. (1977). 'Referencing as persuasion'. Social Studies of Science 7 (1), pp. 113-122. URL: http://www. jstor .org/stable/284636.

Goldman, A. I. (2006). Simulating Minds: The Philosophy, Psychology, and Neuroscience of Mindreading. Oxford: Oxford University Press, U.K.

Gregory, J. and Miller, S. (1998). Science in public: communication, culture, and credibility. New York, U.S.A.: Plenum.

Griggers, C. B. (2009). 'The writing on the screen: A meditation on the Virginia Tech shooting spree: Age-appropriate use of violent first-person computer games'. Semiotica 2009 (177), pp. 189-196. DOI: 10.1515/semi.2009.073.

Groß, M. and Stauffacher, M. (2014). 'Transdisciplinary environmental science: problem-oriented projects and strategic research programs'. Interdisciplinary Science Reviews 39 (4), pp. 299-306. DOI: 10.1179/0308018814Z.00000000093.

Gruber, D. R. (2014). 'Mirror neurons in a Group Analysis "Hall of Mirrors"'. Technical Communication Quarterly 23 (3), pp. 207-226. DOI: $10.1080 / 10572252.2013 .816489$. 
Hickok, G. (2009). 'Eight problems for the mirror neuron theory of action understanding in monkeys and humans'. Journal of Cognitive Neuroscience 21 (7), pp. 1229-1243. DOI: 10.1162/jocn. 2009.21189.

- (2014). The Myth of Mirror Neurons: The real neuroscience of communication and cognition. New York, U.S.A.: W.W. Norton \& Co.

Hickok, G. and Hauser, M. (2010). '(Mis)understanding mirror neurons'. Current biology: CB 20 (14), R593-R594. DOI: 10.1016/j . cub.2010.05.047.

Iacoboni, M. (2008). Mirroring people: the new science of how we connect with others. New York, U.S.A.: Farrar, Straus and Giroux.

Jacob, P. (2008). 'What Do Mirror Neurons Contribute to Human Social Cognition?' Mind and Language 23 (2), pp. 190-223.

Jajdelska, E., Butler, C., Kelly, S., McNeill, A. and Overy, K. (2010). ‘Crying, Moving, and Keeping It Whole: What Makes Literary Description Vivid?' Poetics Today 31 (3), pp. 433-463. DOI: 10.1215/03335372-2010-002.

Johnson, J. M. and Littlefield, M. M. (2011). 'Lost and found in translation: popular neuroscience in the emerging neurodisciplines'. In: Sociological Reflections on the Neurosciences. Wagon Lane, U.K.: Emerald Group Publishing Limited, pp. 279-297.

Knorr, C. K. (1999). Epistemic Cultures: How the sciences make knowledge. Cambridge, MA, U.S.A.: Harvard University Press.

Kosonogov, V. (2012). 'Why the Mirror Neurons Cannot Support Action Understanding'. Neurophysiology 44 (6), pp. 499-502. DOI: 10.1007/s11062-012-9327-4.

Kuhlen, A. (December 2014). Interview "On Inter-disciplines". URL: http://www. neurohuman.com.

Latour, B. (1987). Science in action: How to follow scientists and engineers through society. Cambridge, MA, U.S.A.: Harvard University Press.

- (1997). 'A well-articulated primatology: Reflexions of a fellow traveler'. In: Primate encounters: Models of science, gender, and society. Ed. by S. C. Strum and L. M. Fedigan. Chicago, IL, U.S.A.: The University of Chicago Press, pp. 358-381.

- (2005). Reassembling the social: An introduction to actor-network-theory. Oxford, U.K.: Oxford University Press.

Lingnau, A., Gesierich, B. and Caramazza, A. (2009). 'Asymmetric fMRI adaptation reveals no evidence for mirror neurons in humans'. Proceedings of the National Academy of Sciences 106 (24), pp. 9925-9930. DOI: 10.1073/pnas .0902262106.

Mahon, B. Z. and Caramazza, A. (2005). 'The orchestration of the sensory-motor systems: Clues from Neuropsychology'. Cognitive Neuropsychology 22 (3), pp. 480-494. DOI: $10.1080 / 02643290442000446$.

Melrose, R. (2006). 'Walking and talking: Traces of the body in the grammar and lexis of spontaneous spoken English'. Semiotica 2006 (162), pp. 341-369. DOI: 10.1515/SEM. 2006.084.

Merriam, S. (1998). Qualitative research and case study applications in Education. San Francisco, U.S.A.: Jossey-Bass.

Michael, J. (2012). 'Mirror systems and simulation: a neo-empiricist interpretation'. Phenomenology and the Cognitive Sciences 11 (4), pp. 565-582. DOI: 10.1007/s11097-012-9253-3.

Mukamel, R., Ekstrom, A. D., Kaplan, J., Iacoboni, M. and Fried, I. (2010). 'Single-neuron responses in humans during execution and observation of actions'. Current biology 20 (8), pp. 750-756. DOI: 10.1016/j . cub. 2010 . 02 . 045. 
Murphy, F. C., Nimmo-Smith, I. and Lawrence, A. D. (2003). 'Functional neuroanatomy of emotions: A meta-analysis'. Cognitive, Affective, $\mathcal{E}$ Behavioral Neuroscience 3 (3), pp. 207-233. DOI: 10.3758/CABN . 3.3.207.

Negri, G. A. L., Rumiati, R. I., Zadini, A., Ukmar, M., Mahon, B. Z. and Caramazza, A. (2007). 'What is the role of motor simulation in action and object recognition? Evidence from apraxia'. Cognitive Neuropsychology 24 (8), pp. 795-816. DOI: 10.1080/02643290701707412.

Papoulias, C. and Callard, F. (2010). 'Biology's Gift: Interrogating the Turn to Affect'. Body E Society 16 (1), pp. 29-56. DOI: 10.1177/1357034X09355231.

Pardo, J. S. (2012). 'Reflections on Phonetic Convergence: Speech Perception does not Mirror Speech Production'. Language and Linguistics Compass 6 (12), pp. 753-767. DOI: 10.1002/lnc3.367.

Pezzulo, G. and Castelfranchi, C. (2009). 'Thinking as the control of imagination: a conceptual framework for goal-directed systems'. Psychological Research PRPF 73 (4), pp. 559-577. DOI: 10.1007/s00426-009-0237-z.

Powell, B. D. (2007). 'Neural Performance: Reconsidering Agency as the Embodiment of Neural Nets'. Text and Performance Quarterly 27 (2), pp. 107-123. DOI: $10.1080 / 10462930701251157$.

Priest, S. H. (2006). 'Public Discourse and Scientific Controversy A Spiral-of-Silence Analysis of Biotechnology Opinion in the United States'. Science Communication 28 (2), pp. 195-215. DOI: 10.1177/1075547006293918.

Proctor, R. (2008). Agnotology: The making and unmaking of ignorance. Stanford, U.S.A.: Stanford University Press.

Ramsay, S. (2011). Reading machines: Toward an algorithmic criticism. U.S.A.: University of Illinois Press.

Rickert, T. (2012). Ambient rhetoric: The attunements of rhetorical being. Pittsburgh, U.S.A.: University of Pittsburgh Press.

Rizzolatti, G., Fadiga, L., Fogassi, L. and Gallese, V. (1999). 'Resonance behaviors and mirror neurons'. Archives Italiennes De Biologie 137 (2-3), pp. 85-100. URL: http://www .architalbiol.org/aib/article/view/13785.

Rizzolatti, G. and Craighero, L. (2004). 'The mirror-neuron system'. Annual Review of Neuroscience 27, pp. 169-192. DOI: 10.1146/annurev. neuro.27.070203.144230.

- (2006). Mirror neuron: A neurological approach to empathy. URL: http://www.robotcub.org/misc/papers/06_Rizzolatti_Craighero.pdf.

Science Daily Staff (6th November 2007). Mirror, Mirror In The Brain: Mirror Neurons, Self-understanding And Autism Research. ScienceDaily. URL: http://www.sciencedaily.com/releases/2007/11/071106123725.htm (visited on 10th May 2012).

Tai, Y. F., Scherfler, C., Brooks, D. J., Sawamoto, N. and Castiello, U. (2004). 'The Human Premotor Cortex Is 'Mirror' Only for Biological Actions'. Current Biology 14 (2), pp. 117-120. DOI: 10.1016/j . cub. 2004.01.005.

Traxler, M. J. (2013). 'The Role of the Putative Mirror Neuron System in Language Comprehension'. Language and Linguistics Compass 7 (8), pp. 409-422. DOI: 10.1111/lnc3.12040.

Turella, L., Pierno, A. C., Tubaldi, F. and Castiello, U. (2009). 'Mirror neurons in humans: consisting or confounding evidence?' Brain and Language 108 (1), pp. 10-21. DOI: 10.1016/j. bandl.2007.11.002.

Umiltà, M. A., Kohler, E., Gallese, V., Fogassi, L., Fadiga, L., Keysers, C. and Rizzolatti, G. (2001). 'I Know What You Are Doing: A Neurophysiological Study'. Neuron 31 (1), pp. 155-165. DOI: 10.1016/S0896-6273 (01) 00337-3. 
US News Staff (3rd August 2011). The Role of Mirror Neurons in Human Behavior. US News. URL: http://www. usnews. com/science/articles/2011/08/03/the-rol e-of-mirror-neurons-in-human-behavior (visited on April 2012).

Wicker, B., Keysers, C., Plailly, J., Royet, J.-P., Gallese, V. and Rizzolatti, G. (2003). 'Both of Us Disgusted in My Insula: The Common Neural Basis of Seeing and Feeling Disgust'. Neuron 40 (3), pp. 655-664. DOI: 10.1016/S0896-6273(03)00679-2.

Author

David R. Gruber is a Senior Lecturer at Massey University. His research bridges rhetoric, science and technology studies, and the critical neurosciences. He has published in Public Understanding of Science, Rhetoric Society Quarterly, Journal of Medical Humanities, among others. E-mail: grubermailbox@gmail.com.

How to cite

Gruber, D. R. (2016). 'The extent of engagement, the means of invention: measuring debate about mirror neurons in the humanities and social sciences'.

JCOM 15 (02), A01. 